\title{
PARENTAL GENETIC DISTANCE BASED ON MOLECULAR MARKERS AND ITS RELATIONSHIP WITH HETEROSIS IN RICE \\ EL-Refaee, Y.Z. ${ }^{* 1}$; M. M. Shehab ${ }^{1}$; A. M. $\operatorname{Reda}^{1}$ and A. M. Fayed $^{2}$ \\ 1- Rice Research \& Training Center, Field Crops Res. Inst., Agr. 1 Res. Center, Egypt. \\ 2- Molec. Biol. Dep. Genetic Engineering and Biotech. Res. Ins., Menofiya Uni. Egypt. \\ *Corresponding author:elrefaeey@yahoo.co.in
}

\begin{abstract}
This study was conducted at the farm of Sakha Agriculture Research Station during 2011 and 2012 growing seasons using nine parents and 36 hybrid combinations to study the relationship between genetic distances of parental genotypes and heterosis. The genetic distance of parental genotypes was determined by using functional genes markers related to yield traits. The correlation between genetic distance of parental genotypes and heterosis values was detected by determining 36 hybrids performance. The results indicated that the genetic distance was significant and positive correlated with grain yield/plant for midparent and standard heterosis estimates of $\mathrm{r}=0.46^{*}$ and $\mathrm{r}=0.35^{*}$, respectively. While the parental genetic distance was not significant correlated with heterosis for some other traits among them: number of productive panicles/plant, 1000-grain weight, fertility percentage $\%$ and number of grains/panicle. Thus, the correlation coefficients was not sufficient enough among the parental genotypes for these traits and was not suitable to use molecular potentiality for heterosis prediction.
\end{abstract}

Key words: rice; traits; parental genetic distance; heterosis; molecular markers; correlation.

\section{INTRODUCTION}

Rice is one of the most important food crops in the world and it's consider as the food source for more than one third of world's population (Singh and Singh, 2008). Ram et al., (2007) suggested that in order to meet the demand for food in the future cause to the expectation of increased population of the world, there is an urgent need for increasing rice production. Development of hybrids through the exploitation of heterosis is considered as one of the greatest breakthroughs in plant breeding to increase its production. How to predict the hybrids performances and to select convenient parents have been interesting for rice breeders. The genetic variations among the parental genotypes are the first reason for heterosis. Thus, breeders studied the genetic variation among parental genotypes and their relationship extensively with the prediction of the heterotic performances of $F_{1}$ hybrids. Moreover, restrictions of traditional breeding methods depending on parental genetic differences relationships, geographic origin and morphological traits (Hinze et al, 2003) made a difficult task for heterosis prediction. The progress of methodology for molecular markers enhances the tools for heterosis prediction, which increases the rice breeding efficiency. Sun et al, (2000) found that heterosis from the better-parent was highly correlated with indica-japonica differences of parental genotypes at level of DNA rather than the morphology, suggesting that the techniques of molecular markers are a good predictor for heterosis than morphological characters. In fact, to use molecular markers for determining the genetic variations among parental genotypes and their relationship with heterosis prediction have been critically discussed with inconsistent results in rice. Cai et al, 2005; Zhao et al, 2009; Zhang Tao et al (2010) and with other studies reported that genetic distances which determined through molecular markers were high and positive correlated with heterosis prediction. While, Zhang et al, 2006 and Liao et al (1998) found that there was no correlation between genetic distance which determined by molecular markers and $F_{1}$ heterosis estimates, indicating that the genetic distance is not a suitable predictor for heterosis. The genetic distance might be utilize for heterosis prediction when the particular heterozygosity among parental genotypes was high correlated with performance of hybrids (Zhang et al 1995). However, the relationship could be affected by the genetic variation among parents and the difficult of genetic mechanisms controlling heterosis. In previous studies, the genetic differentiations among parental genotypes were detected with non-specific molecular markers. These genetic differences which were associated with molecular markers at random loci would be the reason of inconsistent results of determining the correlation between parental genetic distance and heterosis. In fact, heterosis is generally caused by yield and its traits, which would be suitable to determine the relationship between the genetic variations among the parental genotypes and heterosis for yield by the genetic distance which detected through whole rice genome. Therefore, it would be more reliable to determine the parental genotypes differences based on molecular markers for functional genes of yield. Recently, differents genomic tools such molecular markers related with heterotic gene blocks, ESTs and heterosis- related gene databases give good opportunities for understanding the molecular basis of heterosis and to improve methodologies for a reliable heterosis prediction (Rajendrakumar et al, 2015).

In this study, Nine rice parental genotypes and 36 combinations were utilized. Twenty functional genes markers were adopted to study the relationship between marker locus heterozygosity and $\mathrm{F}_{1}$ hybrid combinations performance for yield and its traits.

\section{MATERIALS AND METHODS}


Giza182, IR25571-31-1, IR65598-112-2, IR65600-27-1-2-2 and IR65564-44-5-1, and 36 hybrids obtained from the above mentioned parental genotypes, were utilized in this study. The origin, pedigree and type of the parental lines are shown in Table 1.

Table 1: Origin, Pedigree and type of the studied nine rice genotypes.

\begin{tabular}{|c|c|c|c|}
\hline No. & Genotype & Origin and Pedigree & Type \\
\hline 1 & Giza 171 & $\begin{array}{c}\text { Egypt } \\
\text { (Nahda/Calady40) }\end{array}$ & Japonica \\
\hline 2 & Sakha101 & $\begin{array}{c}\text { Egypt } \\
\text { (Giza176/Milyang79) }\end{array}$ & Japonica \\
\hline 3 & Giza177 & $\begin{array}{c}\text { Egypt } \\
\text { (Giza171/Yomji No.1//Pi No.4) }\end{array}$ & Japonica \\
\hline 4 & Giza178 & $\begin{array}{c}\text { Egypt } \\
\text { (Giza175/Milyang 49) }\end{array}$ & Indica/Japonica \\
\hline 5 & Giza182 & $\begin{array}{c}\text { Egypt } \\
\text { (Giza181/IR39422-161-1-3//Giza181) }\end{array}$ & Indica \\
\hline 6 & IR25571-31-1 & $\begin{array}{c}\text { IRRI } \\
\text { (IR9124-209-2-2/IR2307-247-2-2-3) }\end{array}$ & Indica \\
\hline 7 & IR65598-112-2 & $\begin{array}{c}\text { IRRI } \\
\text { (Shen-nung-89-366/Genijah Wangkal) (B 4667) }\end{array}$ & Tropical-japonica \\
\hline 8 & IR65600-27-1-2-2 & $\begin{array}{c}\text { IRRI } \\
\text { (Shen-nung-89-366/Ketan Lumbu) (B 4687) }\end{array}$ & Tropical-japonica \\
\hline 9 & IR65564-44-5-1 & $\begin{array}{c}\text { IRRI } \\
\text { (Shen-nung-89-366/Gundil Kuning) }\end{array}$ & Tropical-japonica \\
\hline
\end{tabular}

Field Experiments:

The present investigation was carried out at Research Farm of Agriculture Research Station, Sakha, Kafr ElSheikh, Egypt, during 2011 and 2012 summer seasons and at the Genetic Engineering and Biotechnology Research Institute, Minufiya University, Sadat City, Egypt. The nine parental genotypes were grown in three successive sowing dates with two weeks interval to synchronize the flowering times. A partial diallel crosses was carried out among them (without reciprocals) that was made to produce 36 hybrids. Crossing techniques were done using the method of Jodon (1938) as modified by Butany (1961). A total of $36 F_{1}$ crosses were obtained and seeds were separately harvested for each cross. Seedlings of the parental genotypes as well as their hybrid combinations were transplanted to a 3-row plot with a plant spacing of $20 \times 20 \mathrm{~cm}$. The experimental design was a randomized complete blocks design (RCBD) with three replications were used. Data of number of grains per panicle, number of productive panicles per plant, 1000-grain weight, spikelets fertility $\%$ and grain yield per plant were recorded.

Molecular markers analysis:

DNA was extracted from each genotype using CTAB (Cetyl-tetramethyl ammonium bromide) method according to Murray and Thompson (1980) at 21 days age. Twenty SSR markers related to yield traits located on nine chromosomes were detected to investigate the nine parental genotypes for polymorphism. This was done on the basis of published rice microsatellite framework map as presented in Table 2. The SSR analysis was performed according to the protocol of Ravi et al. (2003).

Table 2: Features of polymorphic SSR primers used in the current study.

\begin{tabular}{|c|c|c|c|c|}
\hline Marker Name & Chro. No. & F. primer sequences & R. primer sequences & Functional gene \\
\hline RM 5 & 1 & TGCAACTTCTAGCTGCTCGA & GCATCCGATCTTGATGGG & Yld 1.1 \\
\hline RM 246 & 1 & GAGCTCCATCAGCCATTCAG & CTGAGTGCTGCTGCGACT & Pss 1.1 \\
\hline RM 302 & 1 & TCATGTCATCTACCATCACAC & ATGGAGAAGATGGAATACTTGC & Gw 1.1 \\
\hline RM 472 & 1 & CCATGGCCTGAGAGAGAGAG & AGCTAAATGGCCATACGGTG & $G p l 1.1$ \\
\hline RM 145 & 2 & CCGGTAGGCGCCCTGCAGTTTC & CAAGGACCCCATCCTCGGCGTC & $G W 2$ \\
\hline RM 213 & 2 & ATCTGTTTGCAGGGGACAAG & AGGTCTAGACGATGTCGTGA & $G p l 2.1$ \\
\hline RM 263 & 2 & CCCAGGCTAGCTCATGAACC & GCTACGTTTGAGCTACCACG & Ftg -1 \\
\hline RM 411 & 3 & ACACCAACTCTTGCCTGCAT & TGAAGCAAAAACATGGCTAGG & Gs 3 \\
\hline RM 571 & 3 & GGAGGTGAAAGCGAATCATG & CCTGCTGCTCTTTCATCAGC & Gw 3.2 \\
\hline RM 252 & 4 & TTCGCTGACGTGATAGGTTG & ATGACTTGATCCCGAGAACG & Qpn 4.4 \\
\hline RM 17 & 5 & TGCCCTGTTATTTTCTTCTCTC & GGTGATCCTTTCCCATTTCA & qSW 5 \\
\hline RM 26 & 5 & GAGTCGACGAGCGGCAGA & CTGCGAGCGACGGTAACA & $q G W-5$ \\
\hline RM 289 & 5 & TTCCATGGCACACAAGCC & CTGTGCACGAACTTCCAAAG & $q G W 5$ \\
\hline RM 70 & 7 & GTGGACTTCATTTCAACTCG & GATGTATAAGATAGTCCC & Ghd 7 \\
\hline RM 201 & 9 & CTCGTTTATTACCTACAGTACC & СТACСТССТTTCTAGACCGATA & $G w 9$ \\
\hline RM 205 & 9 & CTGGTTCTGTATGGGAGCAG & CTGGCCCTTCACGTTTCAGTG & Gw 9.2 \\
\hline RM 228 & 10 & CTGGCCATTAGTCCTTGG & GCTTGCGGCTCTGCTTAC & $g w 1 O b$ \\
\hline RM 20 & 11 & ATCTTGTCCCTGCAGGTCAT & GAAACAGAGGCACATTTCATTG & gw1 1.1 \\
\hline RM 202 & 11 & CAGATTGGAGATGAAGTCCTCC & CCAGCAAGCATGTCAATGTA & Ppl 1.1 \\
\hline RM 206 & 11 & CCCATGCGTTTAACTATTCT & CGTTCCATCGATCCGTATGG & $q G W-11-1$ \\
\hline
\end{tabular}


PCR amplifications were performed in a $20 \mu$ leaction volume: each reaction contained $1.0 \mu 1$ template DNA; $0.10 \mu 1$ Taq polymerase, $4 \mu 1$ of $5 \mathrm{X}$ buffer, $1 \mu 1$ of $10 \mathrm{mM}$ of each of the four (dNTPs), $1.0 \mu 1$ of $10 \mathrm{mM}$ forward and reverse primers. The volume was brought up to $20 \mu \mathrm{l}$ by autoclaved double distilled $\mathrm{H}_{2} \mathrm{O}$. The amplification protocol of $5 \mathrm{~min}$ at $94{ }^{\circ} \mathrm{C}, 35$ cycles, was performed with $40 \mathrm{sec}$ at $94^{\circ} \mathrm{C}$; $40 \mathrm{sec}$ at lower annealing temperature of the primer about 50 up to $68{ }^{\circ} \mathrm{C}$; $1 \mathrm{~min}$ at $72{ }^{\circ} \mathrm{C}$, and a final extension step of $10 \mathrm{~min}$ at $72{ }^{\circ} \mathrm{C}$.

\section{Statistical analysis:}

The amplified SSR DNA bands representing different alleles were scored as different genotypes. For each marker, allelic bands were scored as base pairs reference on the 100kb DNA ladder in scoring the bands. Then, base pairs fragments were converted into the binary encoded allelic data to subject the multivariate analyses. The ratios of shared DNA bands and genetic distance were estimated from the allele binary formatted dataset using Nei and Li's coefficient (Nei and Li 1979). Genetic distance was calculated as follows: $\mathrm{GD}_{\mathrm{n}}=1-\left[2 N_{11} /\left(2 N_{11}+N_{10}+N_{01}\right)\right]$ where, $\mathrm{N}_{(1,1)}$ is the number of loci having bands present in both genotypes. $\mathrm{N}_{(1,-)}$ is the number of loci having a band present in the first genotype.

$\mathrm{N}_{(-, 1)}$ is the number of loci having a band present in the second genotype. The parental genotypes were clustered based on the genetic distances using Numerical Taxonomy and Multivariate Analysis system, (NTSYS -pc 2.1; Rolhf, 2000). Polymorphic information content (PIC) values were calculated for each marker based on the allelic frequency detected in the genotypes studied using this formula.

n

$\mathrm{PIC}_{\mathrm{i}}=1-\square \mathrm{P}_{\mathrm{ij}}$

$\mathrm{j} \square 1$

where, Pij is the frequency of the jth allele for ith marker and summation extends over $\mathrm{n}$ alleles. Polymorphic loci were defined as those whose most frequent allele had a frequency of less than0.95. Mid-parent heterosis $\%$ $=(\mathrm{F} 1-\mathrm{X}) / \mathrm{X} \times 100$. Where $\mathrm{F} 1$ is the mean for each hybrid combination. Standard heterosis or heterosis over the check variety $($ Sakha101 $) \%=\left(\mathrm{F}_{1}-\mathrm{CK}\right) / \mathrm{CK} \times 100$

\section{RESULTS}

\section{Analysis of SSR markers:}

Twenty SSR markers were used and showed polymorphic as well as produced 61 alleles. Maximum number of alleles per locus was five, found in RM 206 and its ranged from 2 to 5 with an average of 3.05 as presented in figures 1, 2 and 3 and Table 3. The PIC ranged from 0.346 (RM302 and RM411) to 0.765 (RM206) with an average of 0.54 , indicating the presence of genetic variations among the parents.

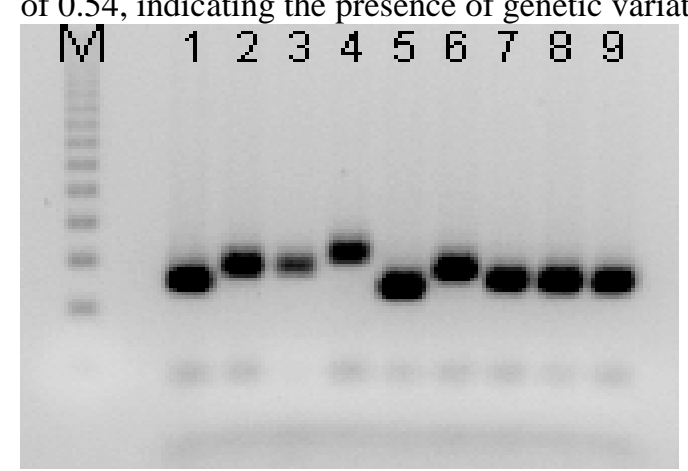

Figure 1. Genomic amplification using primers specific to RM206 showed 5 alleles in all genotypes. M is 100bp ladder, rice parental lines from left to right are: 1)Giza171, 2)Sakha101, 3)Giza177, 4) Giza178, 5)Giza182, 6)IR25751-31-1, 7)IR65598-112-2, 8)IR65600-27-1-2 and 9) IR65564-44-5-1. 


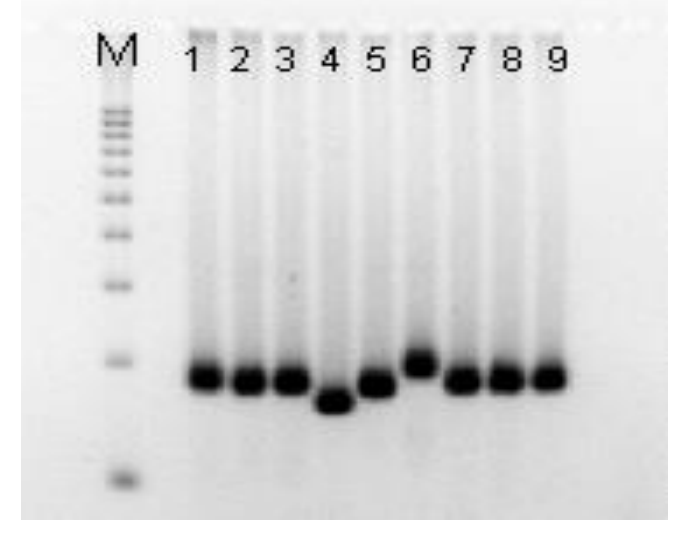

Figure 2. Genomic amplification using primers specific to RM228 showed 4 alleles in all genotypes. M is 100bp ladder, rice parental lines from left to right are: 1)Giza171, 2)Sakha101, 3)Giza177, 4) Giza178, 5)Giza182, 6)IR25751-31-1, 7)IR65598-112-2, 8)IR65600-27-1-2 and 9) IR65564-44-5-1.

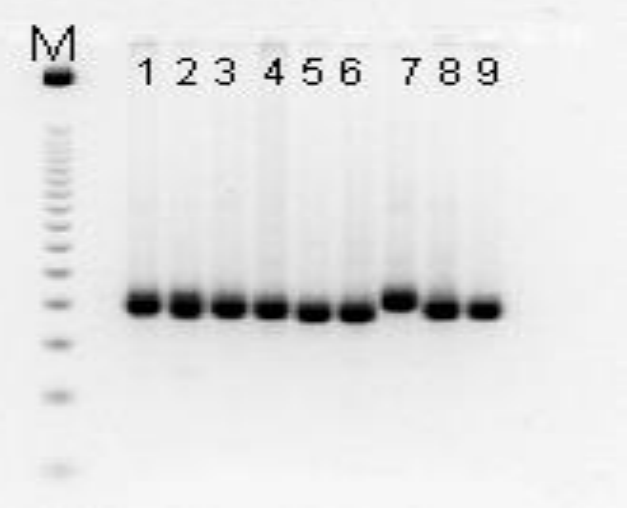

Figure 3. Genomic amplification using primers specific to RM302 showed 2 alleles in all genotypes. M is $50 \mathrm{bp}$ ladder, rice parental lines from left to right are: 1)Giza171, 2)Sakha101, 3)Giza177, 4) Giza178, 5)Giza182, 6)IR25751-31-1，7)IR65598-112-2, 8)IR65600-27-1-2 and 9) IR65564-44-5-1.

Table 3. DNA profiles of SSR markers polymorphism of the nine parental genotypes.

\begin{tabular}{|l|l|l|l|l|}
\hline No. & Chromsome No. & Marker name & No. of alleles & PIC \\
\hline 1 & 1 & RM 5 & 4 & 0.617 \\
\hline 2 & 1 & RM 246 & 3 & 0.667 \\
\hline 3 & 1 & RM 302 & 2 & 0.346 \\
\hline 4 & 1 & RM 472 & 3 & 0.593 \\
\hline 5 & 2 & RM 145 & 3 & 0.568 \\
\hline 6 & 2 & RM 213 & 3 & 0.568 \\
\hline 7 & 2 & RM 263 & 3 & 0.370 \\
\hline 8 & 3 & RM 411 & 2 & 0.346 \\
\hline 9 & 3 & RM 571 & 3 & 0.370 \\
\hline 10 & 4 & RM 252 & 3 & 0.494 \\
\hline 11 & 5 & RM 17 & 3 & 0.494 \\
\hline 12 & 5 & RM 26 & 3 & 0.568 \\
\hline 13 & 5 & RM 289 & 3 & 0.494 \\
\hline
\end{tabular}


J.Agric.Chem.and Biotechn., Mansoura Univ.Vol. 7(3), March, 2016

\begin{tabular}{|l|l|l|l|l|}
\hline 14 & 7 & RM 70 & 4 & 0.667 \\
\hline 15 & 9 & RM 201 & 2 & 0.444 \\
\hline 16 & 9 & RM 205 & 3 & 0.667 \\
\hline 17 & 10 & RM 228 & 4 & 0.667 \\
\hline 18 & 11 & RM 20 & 2 & 0.444 \\
\hline 19 & 11 & RM 202 & 3 & 0.642 \\
\hline 20 & 11 & RM 206 & 5 & 0.765 \\
\hline Total & 9 chromosomes & 20 loci & 61 alleles & \\
\hline Average & & & 3.05 & 0.54 \\
\hline
\end{tabular}

The genetic distance among the nine parental genotypes ranged from 0.113 to 0.724 , with an average of 0.49 as presented in Table 4, indicating moderately high variation among the parents. The genetic distance showed a maximum of 0.724 between Giza171 and IR25571-31-1, and a minimum of 0.113 between Giza171 and Giza177. The genetic distance between Indica genotypes including Giza178, Giza182 and IR25571-31-1 and the other genotypes was high of 0.71 , and Tropical-japonica genotypes showed moderately genetic diversity of 0.64 . The relatively large genetic distance between Japonica genotypes and Indica genotypes and similarly between Indica genotypes and Tropical-japonica genotypes confirmed that the parental genotypes were genetically variable, and would yield significant heterosis in some combinations.

Table 4: Genetic distance among the nine parental genotypes.

\begin{tabular}{|l|l|l|l|l|l|l|l|l|l|}
\hline & $\begin{array}{l}\text { Giza } \\
171\end{array}$ & Sakha101 & Giza177 & Giza178 & Giza182 & $\begin{array}{l}\text { IR25571- } \\
31-1\end{array}$ & $\begin{array}{l}\text { IR65598- } \\
112-2\end{array}$ & $\begin{array}{l}\text { IR65600- } \\
27-1-2-2\end{array}$ & $\begin{array}{l}\text { IR65564- } \\
44-5-1\end{array}$ \\
\hline Giza 171 & 1 & & & & & & & & \\
\hline Sakha101 & 0.188 & 1 & & & & & & & \\
\hline Giza177 & 0.1128 & 0.1712 & 1 & & & & & & \\
\hline Giza178 & 0.7207 & 0.7043 & 0.6926 & 1 & & & & & \\
\hline Giza182 & 0.7121 & 0.6887 & 0.6965 & 0.3398 & 1 & & & & \\
\hline $\begin{array}{l}\text { IR25571- } \\
\text { 31-1 }\end{array}$ & 0.7237 & 0.6887 & 0.7043 & 0.3475 & 0.332 & 1 & & & \\
\hline $\begin{array}{l}\text { IR65598- } \\
112-2\end{array}$ & 0.4163 & 0.4202 & 0.3891 & 0.6459 & 0.6537 & 0.6459 & 1 & & \\
\hline $\begin{array}{l}\text { IR65600- } \\
27-1-2-2\end{array}$ & 0.3696 & 0.3696 & 0.3502 & 0.6615 & 0.6537 & 0.6226 & 0.1795 & 1 & \\
\hline $\begin{array}{l}\text { IR65564- } \\
44-5-1\end{array}$ & 0.4008 & 0.3969 & 0.3813 & 0.642 & 0.642 & 0.5914 & 0.214 & 0.1784 & \multirow{2}{*}{} \\
\hline
\end{tabular}

The nine parental genotypes were clearly clustered into two major categories at the genetic distance of 0.71 . The first category consisted of japonica and tropical-japonica genotypes were clustered together at level of 0.35 genetic differences. While, the second category comprised Indica genotypes as presented in Figure 4. The results of genetic distance for the parental genotypes were agree essentially with their genetic base. Furthermore, the results indicate that SSR markers of functional gene provides a useful tool for germplasm characterization and genetic diversity. Similar findings were reported by Zhao et al, 2002; Zhang, 2007 and Zhang Tao et al 2010. 


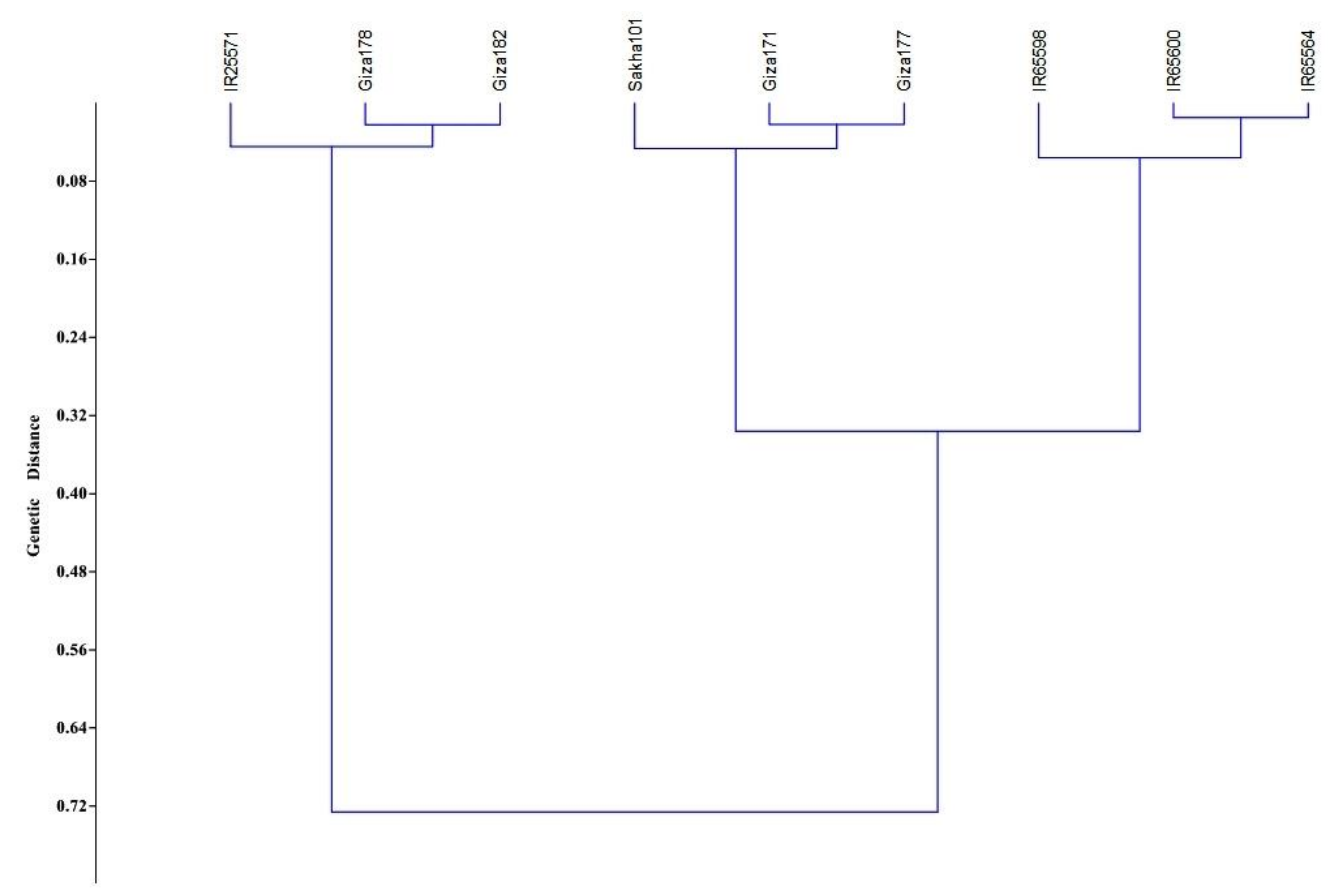

Figure 4. Adendrogram showing the cluster analysis for nine rice genotypes.

Estimates of heterosis over mid-parent and standard heterosis:

The mid-parent heterosis and standard heterosis values for the yield and its traits in the hybrid combinations are presented in Table 5.

Table 5. Mid-parent and standard-heterosis values of yield and its traits.

\begin{tabular}{|c|c|c|c|c|c|c|}
\hline \multirow[t]{2}{*}{ Trait } & \multicolumn{3}{|l|}{ Mid-Parent } & \multicolumn{3}{|c|}{ Standard-heterosis } \\
\hline & $\begin{array}{l}\text { range } \\
(\%)\end{array}$ & $\begin{array}{l}\text { average } \\
(\%)\end{array}$ & $\begin{array}{l}\text { no. } \\
\text { hybrids with } \\
\text { positive and } \\
\text { negative } \\
\text { heterosis } \\
\text { values }\end{array}$ & $\begin{array}{l}\text { range } \\
(\%)\end{array}$ & $\begin{array}{l}\text { average } \\
(\%)\end{array}$ & $\begin{array}{l}\text { no. of hybrids } \\
\text { with positive } \\
\text { and negative } \\
\text { heterosis } \\
\text { values }\end{array}$ \\
\hline $\begin{array}{l}\text { Grain } \\
\text { yield/plant }\end{array}$ & $9.04-40.35$ & 25.18 & $30(6)$ & $-1.38-39.64$ & 10.10 & $24(12)$ \\
\hline $\begin{array}{l}\text { Spikelets } \\
\text { fertility \% }\end{array}$ & $\begin{array}{l}-20.89- \\
17.23\end{array}$ & -2.38 & $15(21)$ & $\begin{array}{l}-28.01- \\
25.7\end{array}$ & -2.82 & $13(23)$ \\
\hline $\begin{array}{l}\text { No. of } \\
\text { productive } \\
\text { panicles/plant }\end{array}$ & $-5.81-54.86$ & 12.76 & $24(12)$ & $\begin{array}{l}-34.22- \\
13.69\end{array}$ & -9.37 & $16(20)$ \\
\hline $\begin{array}{l}\text { No. of } \\
\text { grains/panicle }\end{array}$ & $5.11-52.12$ & 22.26 & $28(8)$ & $\begin{array}{l}22.48- \\
87.26 \\
\end{array}$ & 48.01 & $33(3)$ \\
\hline $\begin{array}{l}\text { 1000-grain } \\
\text { weight }\end{array}$ & $0.83-13.93$ & 10.57 & $33(3)$ & $\begin{array}{l}-14.96- \\
12.09\end{array}$ & 3.33 & $16(20)$ \\
\hline
\end{tabular}

\section{Estimates of mid-parent heterosis:}

The Mid-parent heterosis values for number of grains/panicle varied from $-5.11 \%$ to $52.12 \%$ and followed by grain yield per plant $(9.04 \%$ to $40.35 \%)$ whereas that for spikelets fertility\% varied from $-5.04 \%$ to $24.58 \%$. Maximum number combinations with positive heterosis values was apparent for 1000-grain weight among all the five yield traits, where 33 hybrid combinations showing positive heterosis, followed by grain yield per plant which was apparent in 30 hybrid combinations.

\section{Estimates of standard- heterosis:}

Standard-heterosis values for no. of grains/panicle which varied from $22.48 \%$ to $87.26 \%$. An average of $48.01 \%$, and 33 hybrids had more number of grains per panicle than Sakha 101 which was used as the control; in the same trend standard heterosis values for grain yield per plant ranged from $-1.38 \%$ to $39.64 \%$. An average of $10.10 \%$, and apparent in 24 combinations showing higher grain yield per plant than Sakha101. The performance of some 
combinations for spikelets fertility\%, 1000-grain weight and no. of productive panicles/plant were good and positive. These findings indicating that these particular combinations would be of great value in applications.

\section{Correlation between genetic distance of parental genotypes and heterosis values:}

Correlation analysis between genetic distance of parental genotypes and hybrids performance indicated that the genetic distance of parental genotypes was approximately correlated with either mid-parent or standard-heterosis values for yield traits as presented in Table 6.

Table 6. Correlation coefficients between genetic distance of parents and heterosis values.

\begin{tabular}{|l|l|l|}
\hline Trait & Mid-Parent & Standard-heterosis \\
\hline Grain yield/plant & $0.46^{*}$ & $0.35^{*}$ \\
\hline Spikelets fertility \% & 0.04 & 0.037 \\
\hline No. of productive panicles/plant & $0.189-$ & $-0.374^{*}$ \\
\hline No. of grains/panicle & 0.05 & 0.17 \\
\hline 1000-grain weight & $0.153-$ & -0.114 \\
\hline
\end{tabular}

$*, p<0.05$

Correlation coefficients values between genetic distance of parental genotypes and hybrids heterosis were positive for grain yield/plant, spikelets fertility\% and no. of grains/panicle. The results indicated that hybrids heterosis for grain yield/plant was positive and significant correlated with genetic distance of parental genotypes $\left(r=0.46^{*}\right.$ and $\left.\mathrm{r}=0.35^{*}\right)$. The above finding indicates that genetic distance of parental genotypes was only reflected in grain yield/plant heterosis values. So, it would be suitable for heterosis prediction using functional gene markers for yield.

\section{DISCUSSION}

Heterosis depends on a particular genetic variation degree and complementary action of parental genes. Generally, the larger genetic distance is, the larger heterosis obtained. Causing to its simplicity in use, molecular markers used widely to predict heterosis. But, there are inconsistent views on relationship between the genetic distance based on molecular markers and heterosis prediction. Smith et al, 1990 and some other researchers in maize confirmed that the genetic distance of parental genotypes associated with molecular markers was proper for heterosis prediction. In the same trend, some researchers found similar results in rice heterosis prediction (Zhang et al, 2000; Cai et al, 2005; Zhao et al, 2009; Zhang Tao et el, 2010). For, Jaikishan I. et al, (2010) studied heterosis prediction for grain yield in rice using 'key' informative EST-SSR markers. They determined the comparative potential of 25 EST-SSR markers and 25 SSR markers to predict heterosis of grain yield in rice by nine CMS lines and 32 restorer lines. The coefficient of polymorphic markers among parental genotypes associated with hyper-variable EST and SSR markers was correlated with standard heterosis of grain yield. They recommended that the 10 'key' informative EST-SSR markers for determining the genetic variations of parents and heterosis prediction. On the other hand, some studies such as Zhu et al, 2001 and Zhang et al, 2006 suggested that the genetic distance based on molecular markers would not be use as a good predictor for heterosis. And other ones reported that by using molecular markers was difficult to predict heterosis, Zhang et al, (1996) and Zhao et al, (1999). These inconsistent views are depended on inconsistent results that obtained from the correlation between the genetic differences related to molecular markers and heterosis, that would be related to the genetic base of genotypes and the difficult of genetic mechanisms controlling heterosis. Moreover, the experimental materials differences, designs and type of molecular markers caused different results. The genetic variations among parental genotypes have a lot of forms, including many loci and traits, although not all loci or traits are associated with yield. So, it was unacceptable that the variation in only one locus or trait among parental genotypes would cause heterosis, or all polymorphic loci were related to heterosis (Liao et al, 1998). Heterosis exploitation in rice generally manifested in yield, so it is useful and might be more reliable using markers associated with yield to analyze the genetic variations and determine the relationship between the genetic distance of parental genotypes and heterosis for yield.

Rajendrakumar et al, (2015), obtained significant and high correlation coefficients between parental differences and heterosis using EST-SSR markers in rice with comparison to genomic SSR markers. Heterosis is supposedly as a result of heterozygosity and then the selection of proper type of markers is very important for determining the genetic differences among the parents. Co-dominant and a single locus marker such as SSRs and SNPs are convenient, since they could estimate the heterozygosity based on the parental genotype alleles. This would also help to detect specific alleles associated with heterosis of various traits that could improve the breeding of inbred rice. Moreover, with the sequencing of crop genomes, these markers could be easily located in the physical map. In contrast, the dominant markers are not informative, since they possess information on the allele of only one parent at specific locus. Such lack of complete allelic information will be a great setback to improve the parental genotypes that aimed at increasing superior alleles.

In this investigation, 20 functional gene markers associated with yield traits were selected to determine the genetic variations among parental genotypes and to analyze the relationship between the genetic distance of parental genotypes and heterosis values. The results indicated that there was significant and positive correlation between the 


\section{EL-Refaee, Y.Z. et al.}

genetic distance and grain yield per plant, which was consistent with the general speculation. Accordingly the obtained results is appropriate to use functional gene markers related to yield for heterosis prediction. In contrast, the genetic distance of parental genotypes was not significantly correlated with heterosis for the other yield traits where their correlation coefficients were not sufficient in this study, suggesting that the genetic distance based on molecular markers might not be suitable to predict heterosis. Other studies confirmed this findings.

\section{CONCLUSIONS}

This study indicated that for utilizing the functional gene markers associated with yield and its traits in order to predict heterosis, selection type of markers and methodologies of heterosis prediction need urgent to be improved. The further development of functional genomics and the establishment of rice saturated genetic and physical maps are essential for the studies in this area.

\section{References}

Butany, W.T. (1961). Mass emasculation in rice. Inter. Rice Comm. Newsletter. 9: 9-13.

Cai J, Lan W. 2005. Using of AFLP marker to predict the hybrid yield and yield heterosis in rice. Chin Agric Sci Bull, 21(4): 39-43.

Hinze L L, Lamkey K R. 2003. Absence of epistasis for grain yield in elite maize hybrids. Crop Sci, 43(1): 46-56.

Huang X B, Tian Z H, Deng Z Q, Zheng J T, Lin C B, Tang J X. 2008. Preliminary identification of a novel Sanming dominant male sterile gene in rice (Oryza sativa L.). Acta Agron Sin, 34(10): 1865-1868.

Jaikishan I., P. Rajendrakumar, M. S. Ramesha, B. C. Viraktamath, S. M. Balachandran, C. N. Neeraja, K. Sujatha, K. Srinivasa Rao, P. Natarajkumar, Y. Hari, K. Sakthivel, A. S. Ramaprasad and R. M. Sundaram. (2010). Prediction of heterosis for grain yield in rice using 'key' informative EST-SSR markers. Plant Breeding 129(1): 108-111.

Jiang L, Guo L B, Jiang H, Zeng D L, Hu J, Wu L W, Liu J, Gao Z Y, Qian Q. 2008. Genetic analysis and finemapping of a dwarfing with withered leaf-tip mutant in rice. J Genet Genom, 35(12): 715-721.

Jodon, N.E. (1938). Experiments on artificial hybridization of rice. J. Amer. Soc. Agron. 30: 249-305.

Liao F M, Zhou K L, Yang H H, Xu Q S. 1998. Genetic difference of parents and its relation to heterosis in hybrid rice. Chin J Rice Sci, 12(4): 193-199.

Murray, M. G. and W. F. Thomposon (1980). Rapid isolation of high molecular weight plant DNA. Nucleic Acid Research, 8:4321-3425.

Nei M, Li W. 1979. Mathematical model for studying genetic variation in terms of restriction endonucleases. Proc Natl Acad Sci USA, 76(10): 5269-5273.

Nul acids Res 8:4321-4325.

Rajendrakumar P., H. Krisha and S. Nadoor.(2015). Prediction of Heterosis in Crop Plants - Status and Prospects. American Journal of Experimental Agriculture. 9(3): 1-16.

Ram, S.G., V. Thiruvengadam and K.K. Vinod (2007). Genetic diversity among cultivars, landraces and wild relatives of rice as revealed by microsatellite markers. J. Appl. Genet. 48(4): 337-345.

Ravi, M.; Geethanjali, S.; Sameeyafarheen, F. and Maheswaran, M. (2003). Molecular marker based genetic diversity analysis in rice (Oryza sativa L.) using RAPD and SSR markers. Euphytica, vol. 133, no. 2, p. 243 -252.

Rohlf, F.J. (2000). NTSYS-PC manual Exter Software, Setauket, New Yourk.

Singh Y. and U.S. Singh. 2008. Genetic diversity analysis in aromatic rice germplasm

Smith O S, Smith J S C, Bowen S L, Tenborg K A, Wall S J. 1990. Similarities among a group of elite maize inbreds as measured by pedigree, F1 grain yield, grain yield, heterosis and RFLPs. Theor Appl Genet, 80(6): 833840 .

Sun C Q, Jiang Y B, Chen L, Wu C M, Li Z C, Wang X K. 2000. Studies on the relationship between heterosis and genetic differentiation in hybrid rice (Oryza sativa L.). Acta Agron Sin, 26(6): 641-649.

Zhang P J, Cai H W, Li H C, Yang L S, Bai Y S, Hu X M, Xu C W. 2000. RAPD molecular markers of rice genetic distance and its relationship with heterosis. J Anhui Agric Univ, 28(6): 697-700, 704.

Zhang Q F, Gao Y J, Saghai Maroof M A, Yang H S, Li X J. 1995. Molecular divergence and hybrid performance in rice. Mol Breeding, 1(2): 133-142.

Zhang Q F, Zhou Z Q, Yang G P, Xu C G, Liu K D, Saghai Maroof M A. 1996. Molecular marker heterozygosity and hybrid performance in indica and japonica rice. Theor Appl Genet, 93(8): 1218-1224.

Zhang T, Han L, Xu J D, Jiang K F, Wu X J, Wang X D, Zheng J K. 2006. Correlation between genetic distance and yield heterosis of hybrid aromatic rice. Sci Agric Sin, 39(4): 831-835.

Zhang T. 2007. QTL mapping of brown rice protein content in a RIL population of rice and analysis of genetic diversity of aromatic rice varieties [PhD Dissertation]. Chengdu: Sichuan Agricultural University.

Zhang Tao, Ni X. L., Jiang K. F., Deng H.F., He Q., Yang Q.H., Yang L., Wang X.Q., Cao Y.J. and Zheng J.K. (2010). Relationship Between Heterosis and Parental Genetic Distance Based on Molecular Markers for Functional Genes Related to Yield Traits in Rice. Rice science, 17(4): 288-295. 
Zhao M F, Li X H, Yang J B. 1999. Relationship between molecular marker heterozygosis and hybrid performance in intra- and inter-subspecific crosses of rice. Plant Breeding, 18(2): 139-144.

Zhao Q Y, Zhu Z, Zhang Y D, Zhao L, Chen T, Zhang Q F, Wang C L. 2009. Analysis on correlation between heterosis and genetic distance based on simple sequence repeat markers in japonica rice. Chin J Rice Sci, 23(2): 141-147.

Zhao Y, Yang K, Cheema A A, Weng Y J. 2002. Evaluation of rice germplsam using SSR markers of functional gene in rice. Sci Agric Sin, 35(4): 349-353.

Zhu Z F, Sun C Q, Jiang T B, Fu Q, Wang X K. 2001. The comparison of genetic divergences and its relationships to heterosis revealed by SSR and RFLP markers in rice (Oryza sativa L.). Acta Genet Sin, 28(8): 738-745.

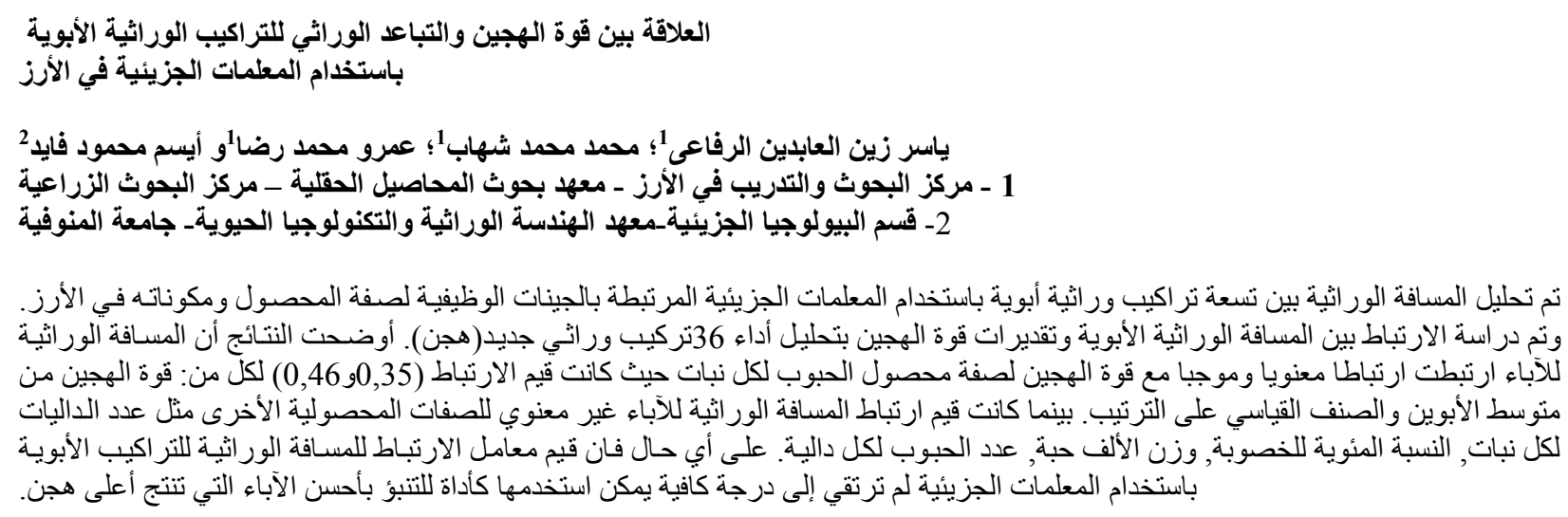

